\title{
EKSPERIMEN PENGKONDISIAN BRINE DI LINGKUNGAN BASA PADA SKALA LAB UNTUK PENCEGAHAN SILICA SCALING DI SUMUR INJEKSI PADA KOLAM PENAMPUNGAN DI PLTP DIENG JAWA TENGAH
}

\author{
CUKUP MULYANA*, RAMDANI, NOWO RIVELI \\ Departemen Fisika, FMIPA, Universitas Padjadjaran \\ Jl. Raya Bandung-Sumedang Km.21 Jatinangor 45363, Sumedang, Jawa Barat \\ *email : c.mulyana55@yahoo.com
}

\begin{abstract}
Abstrak. Pembangkit Listrik Tenaga Panas Bumi (PLTP) berdominasi air di Dieng memiliki permasalahan dengan pengendapan silika (silica scaling), yang terjadi ketika brine keluar dari separator untuk diinjeksikan kembali ke perut bumi. Endapan silika menyumbat rekahan batuan tempat jalur lewatnya air, akibatnya kebutuhan debit air sumber panas bumi terganggu. Konsentrasi silika terlarut dalam brine di PLTP Dieng $1400 \mathrm{mg} / \mathrm{L}$, ketika terjadi penengendapan silika kinerja PLTP terganggu ditandai dengan menurunnya daya pembangkit yang dihasilkan. Penanggulangan yang selama ini dilakukan adalah menampung terlebih dahulu brine di kolam penampungan, membiarkannya untuk beberapa lama agar silikanya mengendap baru di injeksikan ke perut bumi. Tulisan ini melaporkan hasil penelitian perlakuan terhadap sampel brine yang diambil dari lapangan di PLTP Dieng dalam keadaan basa yang dilakukan di laboratorium. Tujuannya adalah mendapatkan pada kondisi $\mathrm{pH}$ berapa silika akan efektip mengendap yang kemudian kelarutannya tetap stabil. Selain itu dicari jenis inhibitor basa apa yang terbilang efektip untuk perlakuan ini. Langkah eksperimen yang dilakukan adalah mengambil sampel brine yang berada di Dieng. Pertama dilakukan pembuatan larutan kerja dari hasil pengenceran natrium metasilika yang diperlukan untuk pembuatan kurva standar absorbansi terhadap konsentrasi silika terlarut. Selanjutnya dilakukan pembuatan sampel brine dengan beberapa pengenceran dan diuji kandungan silika terlarutnya. Langkah berikutnya dilakukan pengkondisian lingkungan basa untuk brine yaitu dengan menambahkan basa kuat $\mathrm{NaOH}$ dan $\mathrm{KOH}$ untuk beberapa nilai $\mathrm{pH}$. Selanjutnya diukur kembali sifat kelarutan silikanya sebagai fungsi waktu. kemudian dilakukan pengujian dengan larutan reagen molibdosilikat, larutan $\mathrm{HCl}$ dan larutan asam oksalat. Konsentrasi silika d dalam sampel birne diperoleh melalui pengukuran absorbansi dengan menggunakan spektrofotometer UV/Vis pada panjang gelombang 410 $\mathrm{nm}$. Berdasarkan hasil penelitian konsentrasi silika yang dalam brine yang keluar dari separator berkisar antara 1312,42 mg/L - 1330,89 mg/L. Kemudian dari hasil pengkondisian lingkungan basa di $\mathrm{pH} 9, \mathrm{NaOH}$ dapat menurunkan konsentrasi silika 49,12\%, sedangkan pengkondisian lingkungan basa dengan $\mathrm{KOH}$ di nilai $\mathrm{pH}$ 9,5 dapat menurunkan konsentrasi silika 18,84\%.
\end{abstract}

Kata kunci : Brine, Silica Scaling, Absorbansi, Konsentrasi Silica, Molibdosilikat

Abstract. Geothermal power plants (PLTP) in Dieng are having the problems of silica deposition (silica scaling), which occurs when the brine comes out from the separator and get injected back to earth. Silica precipitates clog the rocks fracture in the path passed by the water, resulting in the lack of water debit needed to discharge the geothermal sources. The concentration of dissolved silica in the brine of PLTP Dieng is $1400 \mathrm{mg} / \mathrm{L}$, silica scaling would disturb the performance of the powerplant, as indicated by the decreasing generated power. Countermeasures that have been done is to temporarily collect the brine in a storage pond to let the silica settles, before injecting it into the the earth bowels. This paper reports the studies of PLTP Dieng brine samples properties in a basified condition. The goal is to get a $\mathrm{pH}$ value where silica will be effectively settled, which then its 
solubility will remains stable. Also to look for the most effective base inhibitor for this particular treatment. The experimental steps started with taking a brine sample from Dieng. Then, proceed with preparation of a working solution from the resultant of sodium metasilicate dilution, which is required to compute the standard absorbance curve with respect to dissolved silica concentration. Furthermore, brine samples were made with several solubility, and tested the dissolved silica content were tested. The next step is to condition a basic environment for the brine by adding a strong base of $\mathrm{NaOH}$ and $\mathrm{KOH}$ for certain $\mathrm{pH}$ values. Next is to measure again its silica solubility as a function of time, then tested with molybdosilicate reagent solution, $\mathrm{HCl}$ solution and oxalic acid solution The silica concentration in brine samples was obtained through absorbance measurements by using UV / Vis spectrophotometer at $410 \mathrm{~nm}$ wavelength. Based on the results this experiment, the silica concentration in brine that came out from the separator ranged from $1312.42 \mathrm{mg} / \mathrm{L}-1330,89 \mathrm{mg} / \mathrm{L}$. While by introducing a basic environment through a pH $9 \mathrm{NaOH}$, silica concentration decreases by $49,12 \%$, anf through $\mathrm{KOH}$ at $\mathrm{pH}$ value 9,5 silica concentration decreases by $18,84 \%$.

Keywords : Brine, Silica Scaling, Absorbance, Silica Concentration, Molibdosilicate

\section{Pendahuluan}

Menipisnya cadangan energi fosil di Indonesia menyebabkan berbagai upaya dilakukan untuk mencari energi pengganti. Energi Geothermal menjadi memiliki peluang untuk menggantikan energi fosil karena jumlahnya yang melimpah, mudah untuk diubah menjadi energi listrik dalam skala besar, dan termasuk green energy dengan tingkat polusi yang amat rendah [1]. Sebagian besar sumber tenaga geothermal di Indonesia bersifat dominasi air [2]. Permasalahan yang dihadapi oleh pembangkit berdominasi air adalah timbulnya pengendapan silika yang banyak terjadi di berbagai tempat seperti pada pipa injeksi atau di antara posisi sebelum dan setelah separator. Sumber tenaga panas bumi Dieng yang berada di Jawa tengah memiliki permasalahan dengan pengendapan silika (silica scaling). Konsentrasi silika yang terlarut dalam fluida geothermal (brine) terbilang tinggi sebesar 1400 $\mathrm{mg} / \mathrm{L}[2,7]$. Sejumlah pipa tersumbat oleh endapan silika sehinga tidak diinjeksikan kembali melalui sumur injeksi namun ketika diinjeksikan silica tersebut dapat menutupi rekahan-rekahan perut bumi dapat mengalirkan fluida kerja yang mengganggu kinerja pembangkit dan menurunkan daya listrik yang dihasilkan. Permasalahan lainnya terjadi di bagian pipa injeksi, rekahan batuan yang berfungsi untuk melewatkan air yang di injeksikan keperut bumi tertutup oleh endapan silika sehingga cadangan air untuk mengisi reservoir panas di perut bumi berkurang [3]. Untuk menanggulangi permasalahan silica scaling telah dilakukan penelitian pongkondisian brine dalam suasana basa, kemudian diamati sifat kelarutan silikanya yang dilakukan dalam skala lab. Dari hasil penelitian ini diharapkan akan diperoleh nilai $\mathrm{pH}$ yang paling efektip dan jenis basa yang tepat untuk menanggulangi permasalahan pengendapan silika di pembangkit listrik tenaga panas bumi Dieng terutama di daerah pipa setelah separator sebelum pipa injeksi.

Silica scalingdi pembangkit listrik tenaga geothermal umumnya dijumpai pada pipa antara wellhead dengan separator, pipa liquid setelah separator dan sumur reinjeksi. Efek dari silica scaling mengganggu proses pemanfaatan energi geothemal pada pipelines, turbin dan sumur injeksi yang mengakibatkan berkurangnya diameter pipa, sehingga mengurangi laju aliran fluida seperti yang ditunjukkan pada Gambar 1a [5]. Konsentrasi silika terlarut di Dieng Jawa Tengah mencapai $1400 \mathrm{mg} / \mathrm{L}$ pada rentang temperatur $76{ }^{\circ} \mathrm{C}$ sampai $89{ }^{\circ} \mathrm{C}$ dengan $\mathrm{pH}$ rentang 3,20 sampai 3,25 [7]. 
Upaya pencegahan silica scaling dilakukan dengan pembasaan brine selama tertampung di kolam penampungan (pond) seperti yang terlihat pada Gambar 1b sebelum proses injeksi berlangsung guna meningkatkan reaksi pengendapan yang terjadi sehingga kadar silica terlarut dalam brine ketika diinjeksikan sudah turun mencapai170 mg/L atau bahkan lebih kecil lagi. Cara inimerupakan cara yang paling efektif karena tidak menghasilkan resiko apapun. Pembasaan brine bertujuan untuk menaikkan nilai pHyang dapat dilakukan dengan cara menginjeksikan senyawa basa kuat misalnya $\mathrm{KOH}, \mathrm{BaOH}, \mathrm{CaOH}_{2}, \mathrm{NaOH}$ dan lain sebagainya [2].

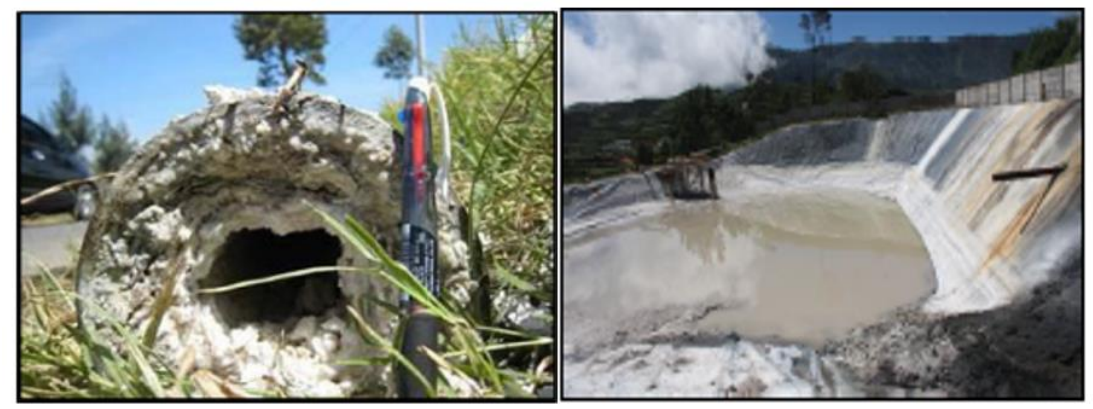

(a) (b)

Gambar 1. (a) Silica Scaling di Pipa Injeksi [8] (b)Kolam Penampungan Brine[3]

\section{Metode Penelitian}

Tahapan penelitian diawali dengan mengambil sampel brine yang keluar dari separator di lapangan PLTP geothermal. Sebelum eksperimen, dilakukan kajian litelatur tentang sifat kelarutan silika sebagai fungsi temperatur dan $\mathrm{pH}$, cara penggunaan reagen molibdosilikat untuk mengukur konsentrasi silika terlarut dengan mengukur absorbansi melalui UV/Vis. Alat yang diperlukan adalah sebagai berikut botol plastik $100 \mathrm{ml}$, magnetik stirer, spektrofotometer UV/Vis, kertas saring $0,45 \mu \mathrm{m}$. Sedangkan bahan kimia yang digunakan adalah asam sulfat 12,06 M, amonium molibdat, asam oksalat, natrium metasilika, aquades, natrium hidroksida $4 \mathrm{M}$, kalium hidroksida $4 \mathrm{M}$, dan sampel brine.

Dipersiapkan tiga larutan reagen yaitu asam klorida $(\mathrm{HCl})$ 1:1 dibuat dengan mencampurkan $50 \mathrm{ml}$ asam klorida dengan pelarut $50 \mathrm{ml}$, amonium molibdat $\left(\left(\mathrm{NH}_{4}\right) 6 \mathrm{Mo}_{7} \mathrm{O}_{24} .4 \mathrm{H}_{2} \mathrm{O}\right)$ dibuat dengan mencampurkan 10 gram amonium molibdat dengan pelarut $100 \mathrm{ml}$ dengan $\mathrm{pH}$ larutan diatur antara $7-8$ dengan larutan $\mathrm{NaOH}$ diaduk menggunakan magnetik stirer pada temperatur $30^{\circ} \mathrm{C}$, selanjutnya asam oksalat $\left(\mathrm{H}_{2} \mathrm{C}_{2} \mathrm{O}_{4}\right)$ dibuat dengan mencampurkan 7,5 gram asam oksalat dengan 100 $\mathrm{ml}$ pelarut. Tahap berikutnya adalah pembuatan dan pengujian larutan kerja silika. Sebanyak 0,473 gram natrium metasilika nonahidrat $\left(\mathrm{Na}_{2} \mathrm{SiO}_{3} \cdot 9 \mathrm{H}_{2} \mathrm{O}\right)$ di campurkan dengan $100 \mathrm{ml}$ pelarut yang disebut larutan stok silica $\left(100 \mathrm{mgSiO}_{2} / \mathrm{L}\right)$. Kemudian dibuat larutan standar satandar silika (1 mgSiO sebanyak $1 \mathrm{ml}$ larutan stok silica di campurkan dengan $100 \mathrm{ml}$ pelarut, larutan ini di namakan larutan standar silica $\left(1 \mathrm{mgSiO}_{2} / \mathrm{L}\right)$. Selanjutnya sebanyak $0 \mathrm{ml}, 5 \mathrm{ml}, 10 \mathrm{ml}, 15 \mathrm{ml}, 20 \mathrm{ml}$, dan $25 \mathrm{ml}$ larutan standar silica $1 \mathrm{mgSiO}_{2} / \mathrm{L}$ di campurkan dengan $100 \mathrm{ml}$ pelarut, larutan ini di namakan larutan kerja silica. Sebanyak $50 \mathrm{ml}$ dari larutan kerja silica yang sudah di saring, kemudian di lakukan pengujian larutan reagen dengan menambahkan $1 \mathrm{ml}$ asam klorida 1:1 dan $2 \mathrm{ml}$ amonium molibdat kemudian di diamkan selama 5 menit. Selanjutnya di tambahkan kembali $2 \mathrm{ml}$ asam oksalat di 
diamkan selama 2 menit. Terakhir di lakukan pengukuran absorbansi menggunakan spektrofotometer UV/Vis pada panjang gelombang $410 \mathrm{~nm}$. (dalam pengukuran larutan kerja silica tidak lebih dari 15 menit karena warna pada larutan kerja silica tidak akan stabil seperti semula). Seluruh perlakuan ini dilakukan pada semua larutan kerja silica dengan volume yang telah ditentukan.

Pengkondisian $\mathrm{pH}$ dan pengujian sampel brine diawali dengan menyiapkan $60 \mathrm{ml}$ sampel brine diukur $\mathrm{pH}$ awalnya. Kemudian dilakukan pengkondisian lingkungan basa dengan menambahkan $\mathrm{NaOH}$ dan $\mathrm{KOH}$ dengan 5 variasi $\mathrm{pH}$ 8; 8,5; 9; 9,5 dan 10. Selanjutnya sampel brine dipanaskan hingga temperatur $80^{\circ} \mathrm{C}$ diputar pada rpm 1000 dalam waktu 120 menit. Setiap 30 menit dilakukan pengambilan sampel brine sebanyak $10 \mathrm{ml}$ untuk disaring, kemudian diambil $1 \mathrm{ml}$ sampel brine untuk dicampur dengan $100 \mathrm{ml}$ pelarut. Selanjutnya $50 \mathrm{ml}$ sampel brine diambil kedalamnya diteteskan $1 \mathrm{ml}$ asam klorida 1:1 dan $2 \mathrm{ml}$ amonium molibdat, di diamkan selama 5 menit. Selanjutnya di tambahkan kembali $2 \mathrm{ml}$ asam oksalat di diamkan selama 2 menit. Terakhir di lakukan pengukuran absorbansi menggunakan spektrofotometer UV/Vis pada panjang gelombang $410 \mathrm{~nm}$. Seluruh perlakuan ini dilakukan pada semua sampel brine dengan $\mathrm{pH}$ yang telah di tentukan.

Pengukuran absorbansi silika terlarut di dalam brine di dalam laboratorium menggunakan spektrofotometer absorbsi UV/Vis yaitu instrumen untuk mengukur absorbansi yang menyerap energi cahaya pada panjang gelombangtertentuoleh atom atau molekul[4].Menurut hukum lambert beer nilai absorbansi cahayaberbanding lurus dengan dengan konsentrasi dan ketebalan bahan atau medium[6].

$$
A=-\log T=\log \frac{i_{o}}{i}=\varepsilon \times C \times d
$$

Dengan A menyatakan koefesien absorbansi, Tadalah koefesien transmisi, $i_{o}$ dan imenyatakan intensitas pengukuran sebelum atau sesudah melewati sampel, $\varepsilon$ adalah koefesien absorbansi molar $(\mathrm{cm} / \mathrm{mg} / \mathrm{L}), \mathrm{C}$ konsentrasi larutan $(\mathrm{mg} / \mathrm{L})$ dan $\mathrm{D}$ adalah ketebalan dari bahan/medium yang di lewati oleh cahaya $(\mathrm{cm})$.

Persamaan 3.1 digunakan untuk menghubungkan nilai konsentrasi yang silika yang terkandung didalam larutan (C) . Nilai hasil pengukuran konsentrasi (C) perlu dikoreksi karena didalam pelarut sudah terkandung silika.

$$
C=\frac{(A \times F P)-b}{a}
$$

Dengan FP menyatakan faktor pengenceran sebesar 100, a adalah kemiringan kurva dan $b$ merupakan koreksi silika terlarut didalam aquades.

\section{Hasil dan Pembahasan}

Hasil penelitian dikelompokkan dalam dua bagian yaitu hasil pengukuran absorbansi silika dari larutan kerja silika dan hasil pengukuran absorbansi silika dari brine hasil pengkondisian $\mathrm{pH}$. Larutan kerja silika memiliki $\mathrm{pH}$ sebesar 7,82 dengan temperatur $23^{\circ} \mathrm{C}$. Hasil pengukuran absorbansi dari enam macam konsentrasi larutan kerja silika ditunjukkan pada Tabel 1. 
Tabel 1. Hasil Pembuatan dan Pengujian Absorbansi Larutan Kerja Silica

\begin{tabular}{cccccc}
\hline No & $\mathrm{pH}$ & $\begin{array}{c}\text { Temperatur } \\
\left({ }^{\circ} \mathrm{C}\right)\end{array}$ & $\begin{array}{c}\text { Volume } \\
(\mathrm{ml})\end{array}$ & $\begin{array}{c}\text { Konsentrasi } \\
(\mathrm{mg} / \mathrm{L})\end{array}$ & Absorbansi \\
\hline & & & 0 & 0,108 \\
& & & & 5 & 0,210 \\
1 & \multirow{2}{*}{7,82} & 23 & \multirow{2}{*}{100} & 10 & 0,514 \\
& & & 15 & 0,733 \\
& & & 20 & 0,795 \\
& & & 25 & 1,040 \\
\hline
\end{tabular}

Grafik absorbansi terhadap konsentrasi untuk larutan kerja silika ditunjukkan pada Gambar 1.

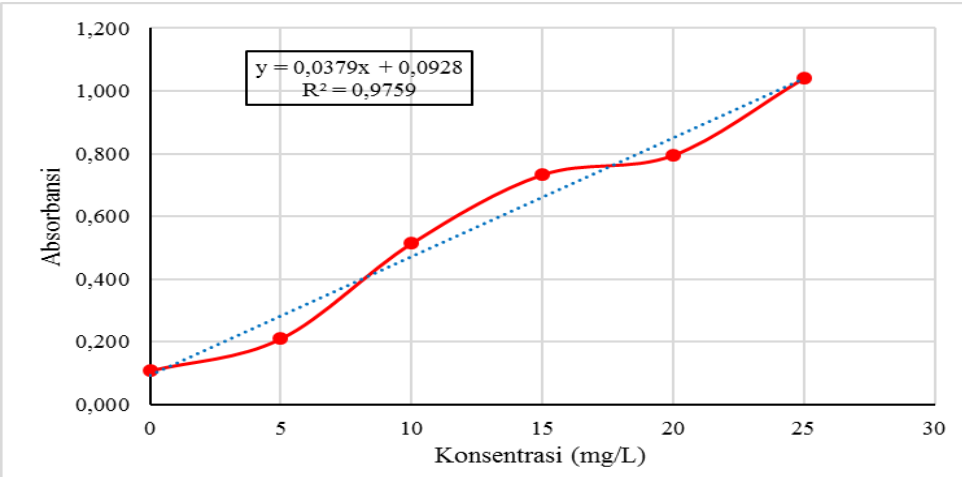

Gambar 1. Grafik Absorbansi terhadap Konsentrasi

Berikut ini adalah kurva konsentrasi silika terlarut terhadap waktu pada lingkungan basa dari lima jenis $\mathrm{pH} \mathrm{NaOH}$ yang berbeda yang ditunjukkan dalam Gambar 2 . Sedangkan kemiringan untuk masing-masing kurva tersebut ditunjukkan oleh Tabel 2 .

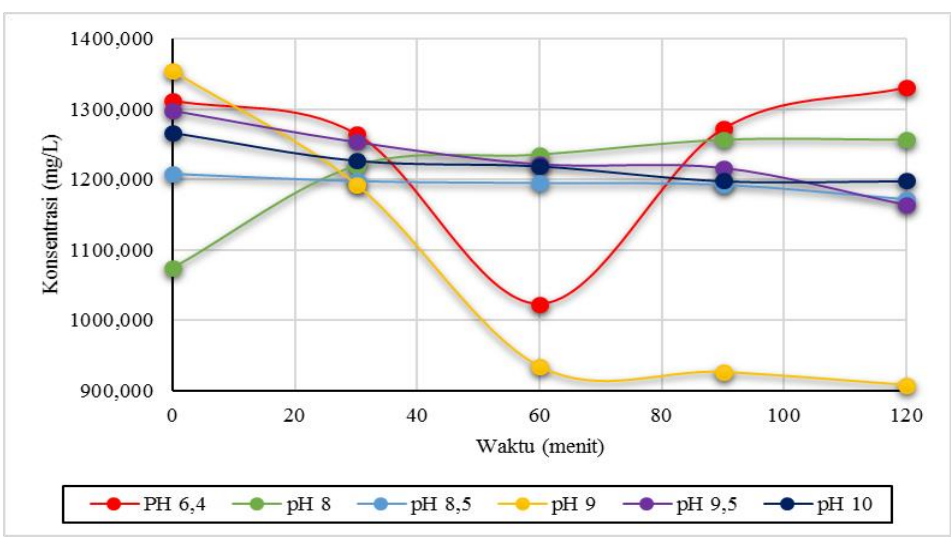

Gambar 2. Kurva Konsentrasi terhadap Waktu 
Tabel 2. Hasil Kemiringan dari Pengkondisian $\mathrm{pH}$ dengan $\mathrm{NaOH}$

\begin{tabular}{ccccc}
\hline No & $\begin{array}{c}\text { Temperatur } \\
\left({ }^{\circ} \mathrm{C}\right)\end{array}$ & $\begin{array}{c}\text { Volume } \\
(\mathrm{ml})\end{array}$ & $\mathrm{pH}$ & Kemiringan \\
\hline 1 & & & 8 & 1,3369 \\
2 & & & 8,5 & $-0,2639$ \\
3 & 80 & 60 & 9 & $-3,8610$ \\
4 & & & 9,5 & $-1,0202$ \\
5 & & & 10 & $-0,5541$ \\
\hline
\end{tabular}

Sedangkan kurva konsentrasi silika terlarut terhadap waktu pada lingkungan basa dari lima jenis $\mathrm{pH} \mathrm{KOH}$ yang berbeda yang ditunjukkan dalam Gambar 3. Kemiringan untuk masing-masing kurva tersebut ditunjukkan oleh Tabel 3.

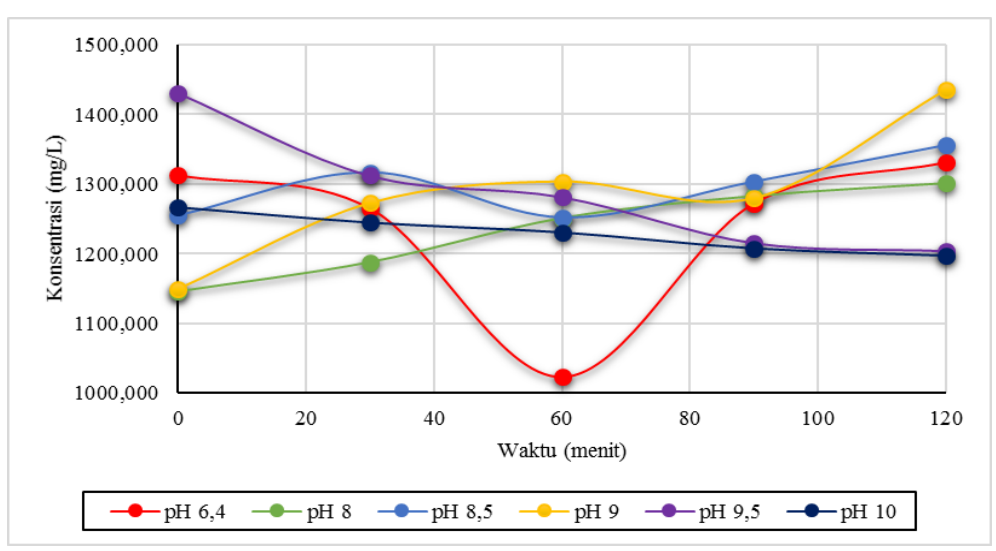

Gambar 3. Kurva Konsentrasi terhadap Waktu

Tabel 3. Hasil Kemiringan dari Pengkondisian $\mathrm{pH}$ dengan $\mathrm{KOH}$

\begin{tabular}{ccccc}
\hline No & $\begin{array}{c}\text { Temperatur } \\
\left({ }^{\circ} \mathrm{C}\right)\end{array}$ & $\begin{array}{c}\text { Volume } \\
(\mathrm{ml})\end{array}$ & $\mathrm{pH}$ & Kemiringan \\
\hline 1 & & & 8 & 1,3544 \\
2 & & & 8,5 & 0,6245 \\
3 & 80 & 60 & 9 & 1,9232 \\
4 & & & 9,5 & $-1,8352$ \\
5 & & & 10 & $-0,5863$ \\
\hline
\end{tabular}

Dari hasil pembuatan dan pengujian larutan kerja silica didapatkan kurva standar bakudengan persamaan berikut yang di peroleh dari hasil kurva fitting pada Gambar 1 dengan nilai koefesien korelasi 0,98 .

$$
y=0,0379 x+0,0928
$$


Kurva absorbansi terhadap konsentrasi yang linier sesuai dengan teori Lambert Beer. Kurva ini di gunakan untuk menentukan nilai konsentrasi larutan sampel brine dari hasil pengukuran yang dihubungkan dengan persamaan 1 yang menghasilkan konsentrasi silika terlarut pada persamaan 2. Kurva konsentrasi untuk berbagai macam $\mathrm{pH}$ dengan basa $\mathrm{NaOH}$ ditunjukkan pada Gambar 2 .

Untuk lingkungan basa dengan $\mathrm{pH} 8$ gradien kemiringannya positif berarti konsentrasi silika terlarut meningkat seiring bertambahnya waktu. $\mathrm{pH} 8$ tidak digunakan dalam pengkondisian brine. Untuk $\mathrm{pH} 8,5$ sampai 10 gradien kemiringannya negatif berarti konsentrasi silika menurun seiring bertambahnya waktu hal ini menunjukkan terjadinya pengendapan silika.Untuk $\mathrm{pH} 9$ kemiringan dari kurva konsentrasi terhadap waktu paling negatif yaitu sebesar $-3,810$ berarti jumlah silika yang mengendap paling besar yaitu dalam waktu 120 menit konsentrasi silika terlarut menurun dari $1353,752 \mathrm{mg} / \mathrm{L}$ menjadi $907,842 \mathrm{mg} / \mathrm{L}$ jumlah silika yang mengendap sebesar 49,118 \%. Untuk $\mathrm{pH}$ ini kestabilan silika terlarut terjadi setelah 60 menit yaitu di tunjukkan oleh bentuk kurva yang relatif datar mulai dari menit ke 60 hingga 120.

Kurva konsentrasi untuk berbagai macam $\mathrm{pH}$ dengan basa $\mathrm{KOH}$ ditunjukkan pada Gambar 3. Untuk lingkungan basa dengan pH 8 sampai 9 gradien kemiringannya positif berarti konsentrasi silika terlarut meningkat seiring bertambahnya waktu. pH 8 sampai 9 tidak digunakan dalam pengkondisian brine. Untuk pH 9,5 dan 10 gradien kemiringannya negatif berarti konsentrasi silika menurun seiring bertambahnya waktu hal ini menunjukkan terjadinya pengendapan silika. Untuk $\mathrm{pH}$ 9,5 kemiringan dari kurva konsentrasi terhadap waktu paling negatif yaitu sebesar $-1,8352$. Sedangkan untuk $\mathrm{pH} 10$ kemiringan sebesar -0,5863. Sehingga jumlah silika yang mengendap paling besar terjadi pada $\mathrm{pH} 9,5$ yaitu dalam waktu 120 menit konsentrasi silika terlarut menurun dari 1433,597 mg/L menjadi 1206,684 $\mathrm{mg} / \mathrm{L}$ jumlah silika yang mengendap sebesar 18,843\%. Untuk $\mathrm{pH}$ ini kestabilan silika terlarut terjadi setelah 60 menit yaitu di tunjukkan oleh bentuk kurva yang relatif datar mulai dari menit ke 60 hingga 120.

\section{Kesimpulan}

Kandungan silica scaling sebelum kolam penampungan brine di PLTP DiengJawa Tengah berkisar antara 1312,415 mg/L hingga 1330,885 mg/L. Untuk mencegah terjadinya silicascaling pada kolam penampungan,pengkondisian $\mathrm{pH}$ brine terbaik harus dilakukan pada $\mathrm{pH} 9$ dengan menggunakan natrium hidroksida, dapat menurunkan konsentrasi silika terlarut sebesar 49,118\%.

\section{Ucapan terima kasih}

Terima kasih kepada DRPMI Universitas Padjadjaran yang telah membantu dalam menyediaan dana untuk penelitian ini. Selain itu kami ucapkan terima kasih kepada Laboratorium Kimia Fisik dan Anorganik, Laboratorium Analisis dan Pemisahan Departemen Kimia, Fakultas Matematika dan Ilmu Pengetahuan Alam, sehingga penelitian ini dapat terlaksanan dengan baik. 


\section{Daftar Pustaka}

1. Indriawati, Katherin dkk, Optimasi Daya Listrik Pada PT Pertamina Geothermal Energy Area Kamojang Jawa Barat.Surabaya:Fakultas Teknologi Industri, ITS.Vol. 1 (2012) p.1-6.

2. Wahyudityo, Rendra dkk, Analisa Scaling Silika Pada Pipa Injeksi Brine Di Lapangan Panas Bumi Dieng Dengan Studi Kasus Di PT.Geo Dipa Energi.Yogyakarta :Fakultas Teknik, Universitas Gajah Mada.Vol.2 (2013) p.1-8.

3. Sukaryadi, Didi, Aspects Of Deposition (Scaling) Of The Binary Cycle Geothermal Power Plants In Dieng Geothermal Field, Central Java.Jakarta Selatan:Pusat Penelitian dan Pengembangan Teknologi Ketenagalistrikan , Energi Baru, Terbarukan, dan Konservasi Energi.Vol. 12 (2013) p. 1-10.

4. Andhika, Muhammad, Studi Pengaruh PH Dan Penggunaan Inhibitor Terhadap Pembentukan Kerak Silika Pada Sampel Air Panas Bumi Lahendong. Depok : Departemen Kimia, Universitas Indonesia (2005).

5. Permana, M. A. Indra, Upaya Penanggulangan Silica Scaling Pada Pembangkit Listrik Geothermal Multi Flashing.Jatinangor:Universitas Padjadjaran (2017).

6. Mantele, Werner, E. Deniz, UV-VIS Absorption Spectroscopy: Lambert-Beer Reloaded.Spectrochimica Acta Part A: Molecular and Biomolecular Spectroscopy Vol.173 (2017) p. 965-968.

7. Pambudi, N. Agung dkk, The Behavior of Silica In Geothermal Brine From Dieng Geothermal Power Plant, Indonesia.Geothermics Vol. 54 (2015) p. 109114.

8. Pambudi, N. Agung dkk, Sustainability of Geothermal Power Plant Combined with Thermodynamic And Silica Scaling Model. Geothermics Vol. 71 (2018) p. 108-117. 